\title{
Coordination of chondrogenesis and osteogenesis by fibroblast growth factor 18
}

\author{
Zhonghao Liu, Jingsong Xu, Jennifer S. Colvin, and David M. Ornitz ${ }^{1}$ \\ Department of Molecular Biology and Pharmacology, Washington University Medical School, \\ St. Louis, Missouri 63110, USA
}

\begin{abstract}
Gain of function mutations in fibroblast growth factor (FGF) receptors cause chondrodysplasia and craniosynostosis syndromes. The ligands interacting with FGF receptors (FGFRs) in developing bone have remained elusive, and the mechanisms by which FGF signaling regulates endochondral, periosteal, and intramembranous bone growth are not known. Here we show that $\mathrm{Fg} f 18$ is expressed in the perichondrium and that mice homozygous for a targeted disruption of $\mathrm{Fgf18}$ exhibit a growth plate phenotype similar to that observed in mice lacking Fgfr3 and an ossification defect at sites that express Fgfr2. Mice lacking either Fgf18 or Fgfr3 exhibited expanded zones of proliferating and hypertrophic chondrocytes and increased chondrocyte proliferation, differentiation, and Indian hedgehog signaling. These data suggest that FGF18 acts as a physiological ligand for FGFR3. In addition, mice lacking Fgf18 display delayed ossification and decreased expression of osteogenic markers, phenotypes not seen in mice lacking Fgfr3. These data demonstrate that FGF18 signals through another FGFR to regulate osteoblast growth. Signaling to multiple FGFRs positions FGF18 to coordinate chondrogenesis in the growth plate with osteogenesis in cortical and trabecular bone.
\end{abstract}

[Key Words: FGF18; FGFR2; FGFR3; endochondral bone growth; chondrocyte; osteoblast]

Received November 28, 2001; revised version accepted February 14, 2002.

Fibroblast growth factors (FGFs) are a family of polypeptides that have important roles in cell growth, differentiation, survival, and numerous developmental processes. The 22 members of the FGF family can be grouped into subfamilies based on greater sequence similarity (Ornitz and Itoh 2001). FGFs can activate one of four high-affinity FGF receptor (FGFR) tyrosine kinases, and FGF subfamilies tend to share similar receptor specificity toward specific alternatively spliced variants of FGFRs (Johnson and Williams 1993; Ornitz et al. 1996; Naski and Ornitz 1998). The discovery that several human skeletal dysplasia syndromes result from point mutations in Fgfr1, Fgfr2, and Fgfr3 suggests that FGFR signaling is an essential component of the regulatory cascades governing skeletal growth and development (Muenke and Schell 1995; Naski and Ornitz 1998). However, the physiologically functional FGF ligand(s) that signal to these receptors have remained elusive.

Skeletal development is highly regulated by a hierarchy of genetic, endocrine, and mechanical regulatory programs (Caplan and Pechak 1987; Hall and Miyake 1992; Erlebacher et al. 1995; Karsenty et al. 2001). In

\footnotetext{
${ }^{1}$ Corresponding author.

E-MAIL dornitz@molecool.wustl.edu; FAX (314) 362-7058.

Article and publication are at http://www.genesdev.org/cgi/doi/10.1101/ gad.965602.
}

mammals, formation of the skull and the medial part of the clavicles is achieved by intramembranous ossification. The remainder of the skeleton develops through the process of endochondral ossification in which cartilage is converted into bone. Cartilage is formed by condensation of mesenchymal cells, which subsequently differentiate into growth plate chondrocytes localized at the ends of the growing bone (Hall and Miyake 2000). Growth plate chondrocytes are arranged in columns that sequentially develop through proliferative, prehypertrophic, and hypertrophic stages. Distal hypertrophic chondrocytes undergo apoptosis and are replaced by trabecular bone and bone marrow (Gibson 1998; Gerber and Ferrara 2000). In a separate process, cortical bone is generated by osteoblasts derived from osteoprogenitor cells in the perichondrium (Caplan and Pechak 1987). An essential feature of skeletal growth is the synchronous regulation of endochondral and cortical bone formation.

Several signaling pathways have been shown to be important for the regulation of bone growth. Parathyroid hormone-related peptide (PTHrP) signaling regulates the process of chondrocyte maturation. Targeted disruption of PTHrP, which is expressed in the periarticular perichondrium, or its receptor, $P T H r P R$, which is expressed in prehypertrophic chondrocytes, results in premature maturation of chondrocytes and a short-limbed dwarfism (Karaplis et al. 1994; Lanske et al. 1996). Indian 
hedgehog (Ihh), which is expressed in prehypertrophic and hypertrophic chondrocytes, induces the expression of PTHrP, and $\mathrm{Ihh}^{-1-}$ mice show delayed chondrocyte maturation and a short-limbed dwarfism, similar to that of $P$ THrP $P^{-/-}$mice (St-Jacques et al. 1999). Ihh also stimulates chondrocyte proliferation in a largely PTHrP-independent pathway (Karp et al. 2000). Fgfr3 is expressed in proliferating and prehypertrophic chondrocytes (Peters et al. 1993; Naski et al. 1998). Fgfr3 ${ }^{-/-}$mice show an expanded growth plate, increased cell proliferation, and increased expression of Ihh (Colvin et al. 1996; Deng et al. 1996; Naski et al. 1998). Mutations activating Fgfr3 or overexpression of an activated Fgfr3 in proliferating chondrocytes results in decreased chondrocyte proliferation and differentiation and decreased Ihh expression and consequently signaling (Naski et al. 1998, Ornitz 2001). These studies suggest that signaling through Fgfr3 negatively regulates chondrocyte proliferation, differentiation, and the activity of Ihh and PTHrP. Fgfr1 and Fgfr2 are expressed in hypertrophic chondrocytes and perichondrium, respectively (Orr-Urtreger et al. 1991; Peters et al. 1992). The precise function of these receptors in bone development is not known.

One interesting but unsolved issue in skeletal development is the identification of the endogenous ligand(s) for FGFRs expressed in the epiphyseal growth plate and perichondrium/periosteum. Some clues may come from the study of limb development in which several FGFs have essential roles (Martin 1998; Naski and Ornitz 1998). For example, Fgf8 and Fgf10 are essential for the progressive outgrowth and patterning of the limb bud (Ohuchi et al. 1997; Min et al. 1998; Lewandoski et al. 2000; Moon and Capecchi 2000). Fgf4, Fgf9, and Fgf17 are also expressed in the developing limb (Martin 1998; Colvin et al. 1999). Fgf8 and Fgf17 are expressed in some skeletal elements (Xu et al. 1999), and Fgf2 is abundantly expressed in chondrocytes (Hill et al. 1992; Twal et al. 1994; Luan et al. 1996). However, gene targeting experiments have not identified a role for these ligands, individually, in either limb or skeletal development (Dono et al. 1998; Ortega et al. 1998; Zhou et al. 1998; Moon et al. 2000; Sun et al. 2000; Xu et al. 2000; Colvin et al. $2001 \mathrm{a}, \mathrm{b})$. Therefore, either these FGFs are redundant or novel FGFs must function in developing bone to regulate FGFRs.

Fgf18 is most closely related to Fgf8 and Fgf17/Ornitz and Itoh 2001). All three of these ligands share similar receptor specificity towards the c splice forms of FGFR1-3 and display overlapping expression patterns in several tissues (Xu et al. 1999, 2000). Here we show that Fgf18 is expressed in the developing perichondrium, making it an attractive candidate to regulate the developing skeleton. We demonstrate that Fgf18 null mice develop a growth plate phenotype similar to that of mice lacking Fgfr3 and that FGF18 negatively regulates the IHH signaling pathway in developing bone. Decreased endochondral and intramembranous ossification suggests that FGF18 positively regulates osteogenesis and/ or osteoblast function through another FGFR. These data demonstrate that FGF18 is an important regulator of both chondrogenesis and osteogenesis and may function to coordinate these developmental processes.

\section{Results}

\section{Fgf18 expression in developing long bone}

The origin of the source of the FGF signal acting on FGFRs in the growth plate is not known. Examination of Fgf18 mRNA expression in developing long bone at E14.5 detected a prominent signal in the perichondrium and developing joints (Fig. 1). The expression of Fgf18 in the perichondrium juxtaposed a source of an FGF ligand with Fgfr3-expressing proliferating chondrocytes, Fgfr1expressing hypertrophic chondrocytes, and Fgfr2-expressing perichondrium and periosteum. This expression pattern suggests a paracrine mechanism of action of FGF18 on chondrocytes and an autocrine or juxtacrine signal to osteoblasts.

\section{Targeting the Fgf18 gene}

To study the in vivo functions of the Fgf18 gene, an Fgf18 null allele was generated through homologous recombination. The Fgf18 targeting strategy eliminated the first exon in the protein coding region, including the translation initiation site and the signal peptide (Fig. 2a). One correctly targeted embryonic stem (ES) cell clone was used to generate chimeric male mice that passed the targeted allele to offspring (Fig. 2b,c). Mice heterozygous for the targeted allele $\left(F g f 18^{-/+}\right)$have a normal phenotype. These mice were bred to produce homozygous mice lacking a functional Fgf18 gene $\left(F g f 18^{-/-}\right)$. Comparison of in situ hybridization patterns in wild-type and $\mathrm{Fg} f 18^{-/-}$ mice showed loss of expression in sites where Fgf18 is normally expressed, such as developing craniofacial tissue (Fig. 2d).

Because $\beta$-galactosidase was introduced into exon 1 of Fgf18, the pattern of $\beta$-galactosidase activity should indicate sites where Fgf18 is normally expressed. Staining for $\beta$-galactosidase in the cranium showed expression along the endosteal and periosteal surfaces of the calvarial bones (Fig. 2e). In developing limb, expression was restricted to the perichondrium, presumptive joint space, and in interdigital mesenchyme (Fig. 2f-i). This expression pattern was consistent with the pattern of Fgf18 mRNA expression and demonstrated no obvious changes in expression in heterozygous versus homozygous mice.

Fgf18 $18^{-/-}$mice survived embryonic development but died in the early neonatal period. Fgf18 ${ }^{-/-}$embryos were about $10 \%-15 \%$ smaller than normal littermates and died of cyanosis within 30 min after birth, probably due to respiratory failure. More than $90 \%$ of $\mathrm{Fgfl}^{-/-}$embryos developed a complete cleft palate (see below). However, cleft palate is normally not associated with early neonatal death, and mice with cleft palate usually can survive up to $24 \mathrm{~h}$ (Peters et al. 1998; Halford et al. 2000). 


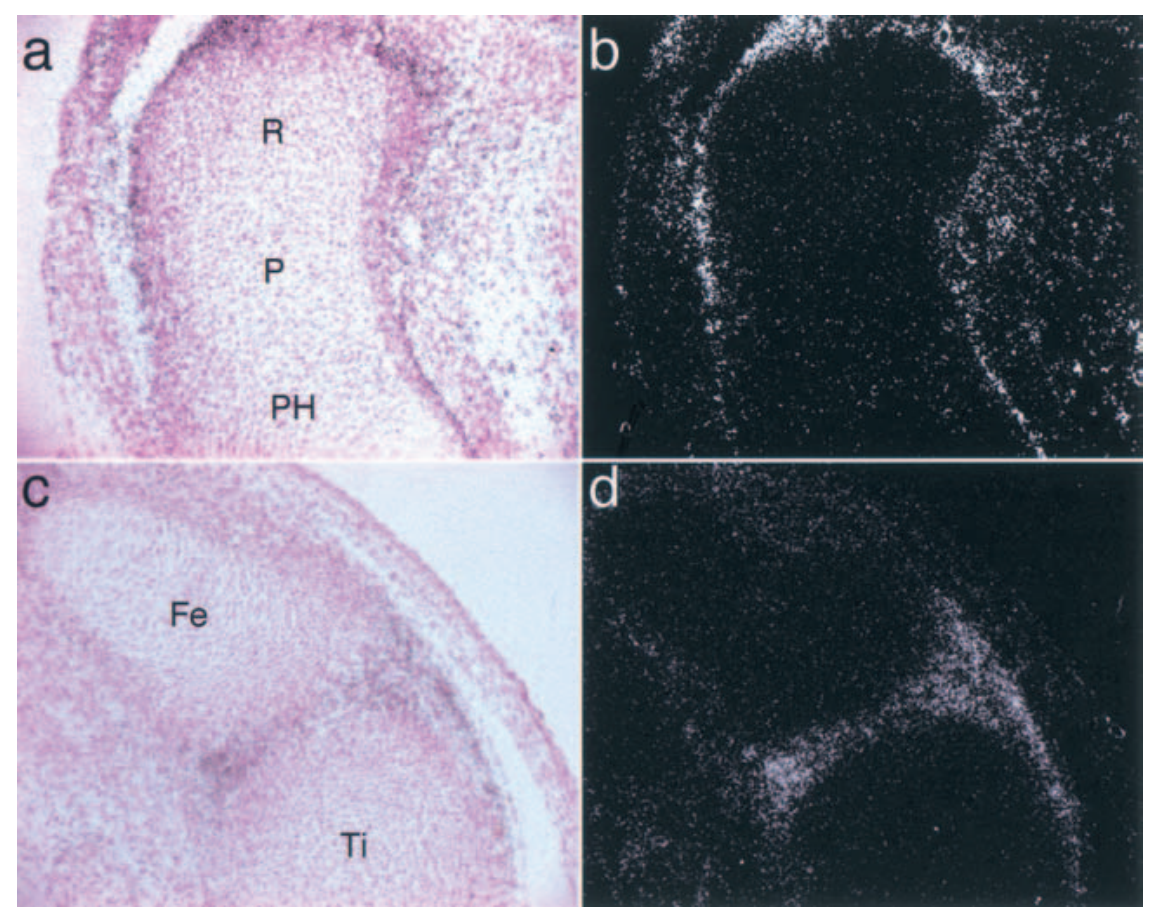

Figure 1. Fgf18 expression in E14.5 developing limb. (a) Proximal humerus growth plate counterstained with hematoxylin and viewed in bright field. (b) Fgf18 in situ hybridization viewed in dark field. Note the expression of Fgf18 in the perichondrium. (c) Knee joint counterstained with hematoxylin and viewed in bright field. (d) Fgf18 in situ hybridization viewed in dark field. Note the expression of Fgf18 in the joint tissue and perichondrium. (R) Reserve chondrocytes; $(\mathrm{P})$ proliferating chondrocytes; $(\mathrm{PH})$ prehypertrophic chondrocytes; (Fe) femur; (Ti) tibia.

\section{Skeletal pathology of Fgf18-targeted mice}

All $\mathrm{Fg} 18^{-/-}$mice exhibited skeletal abnormalities (Fig. 3a). Skeletal preparations at different stages of embryogenesis showed that ossification in $\mathrm{Fg} f 18^{-/-}$mice lagged $\sim 2 \mathrm{~d}$ behind that of wild-type littermates (Fig. 3b,c,e,f). The radius and tibia often showed increased curvature and the ossified portion was shortened in these bones (Fig. 3a,c,e,f). Incomplete development of the fibula was also observed in four of 11 mice (Fig. 3c; data not shown). The ribs of all $\mathrm{Fg} f 18^{-/-}$skeletons were deformed, resulting in reduction of thoracic cavity volume. This defect could contribute to mechanical problems with ventilation and lead to the observed cyanosis and neonatal death. In contrast, skeletons from $\mathrm{Fgfr3}^{-1-}$ mice were more like the wild-type skeletons at this stage of development, but showing some curvature of the tibia and expanded cartilage regions (Fig. $3 \mathrm{~d}$; data not shown).

In addition to defects in the appendicular and axial skeletons, specific defects were also observed in the craniofacial bones and palate. A general reduction in cranial ossification was observed in $\mathrm{Fg} f 18^{-/-}$but not in $\mathrm{Fgfr3}^{-/-}$mice (Fig. 3b). The cranial vault in newborn Fgf18 ${ }^{-/-}$mice was slightly smaller and more rounded, reflecting changes in the size and shape of the calvarial elements. Mesenchymal regions that preform the cranial sutures were widened, probably reflecting decreased growth of calvarial bones (data not shown). The facial skeleton also showed an underdeveloped maxilla (Fig. 3b) and a cleft palate (Fig. 3g,h). Preliminary analysis indicates that the cleft palate may result from a failure of the palatal shelves to properly elevate. These findings were unique to $\mathrm{Fg} / \mathrm{B}^{-/-}$mice and were not observed in $\mathrm{Fgfr}^{-/-}$mice.

\section{Abnormal chondrogenesis in the growth plate of Fgf $18^{-/-}$mice}

In the developing long bone, cells in the growth plate progress through stages of proliferation, hypertrophy, and apoptosis. The distal hypertrophic zone is eventually invaded by vascular elements and replaced with trabecular bone. The defined histomorphological zones of the growth plate outline the various stages of chondrocyte differentiation. Histological analysis showed an overall intact cellular architecture in the growth plate of Fgf $18^{-/-}$embryos. However, the zones of proliferating and hypertrophic chondrocytes were significantly elongated (Fig. 4a,b; Table 1). The height of the distal femoral hypertrophic zone at E16.5 and E18.5 was increased by $60 \%(P<0.005)$ and $37 \%(P<0.02)$ in $F g f 18^{-/-}$mice relative to littermate controls, respectively. The height of the distal femoral proliferating zone was also increased at E16.5 by $14 \%(P<0.02)$ in $F g f 18^{-/-}$mice relative to littermate controls (Fig. 4a,b; Table 1). These data are similar to that observed in $\mathrm{Fgfr}^{-/-}$mice (Colvin et al. 1996).

The expanded proliferating and hypertrophic chondrocyte regions resulted in an enlarged growth plate in Fgf $18^{-/-}$mice compared to normal littermates (Figs. 3, $4 \mathrm{a}, \mathrm{b}$; data not shown). However, the overall length of the long bones was nearly normal. Examination of skeletal preparations demonstrated a delay in the formation of ossification centers in $\mathrm{Fgf18^{-/- }}$ mice, which could account for the shortened mineralized region (Fig. 3).

\section{Fgf18 inhibits chondrocyte proliferation and differentiation}

Long bone growth requires the continuous proliferation and differentiation of chondrocytes in the epiphyseal 
Liu et al.

Figure 2. Generation of an Fgf18-LacZ targeted allele. (a) A schematic representation of the Fgf18 genomic locus, the targeting vector and the mutant allele generated following homologous recombination. (b) Southern blot identification of the Fgf18 targeted allele in embryonic stem cells using a 3' probe and a HindIII digest. (c) Southern blot identification of the Fgf18 targeted allele in tail DNA using a 3' probe and a HindIII digest. The 3 ' probe (as indicated in $a$ ) identifies the wild-type allele as an 11-kb HindIII fragment and the mutant allele as a 4-kb HindIII fragment. (d) In situ hybridization detection of Fgf18 mRNA expression in the developing palatal shelf in wild-type mice (upper panels) and in $\mathrm{Fgfl}^{-/-}$tissue (lower panels). Brightfield and darkfield images are shown. Note the absence of expression in $\mathrm{Fgfl}^{-/-}$tissue (lower panels). (e-i) Staining for $\beta$-galactosidase enzyme activity in Fgf18/ ${ }^{-/+}$cranium and limbs of E14.5 mice. (e) A sagittal section through the parietal bone showing $\beta$-galactosidase enzyme activity in the periosteum and endosteum. $(f, g)$ Dorsal $(f)$ and ventral $(g)$ views of a whole mount-stained limb showing $\beta$-galactosidase enzyme activity in skeletal elements. $(h, i)$ Histological sections through the distal limb stained for $\beta$-galactosidase enzyme activity. A planar section is shown in $(h)$ and a cross section is shown in (i). (D) Dorsal; (V) ventral.

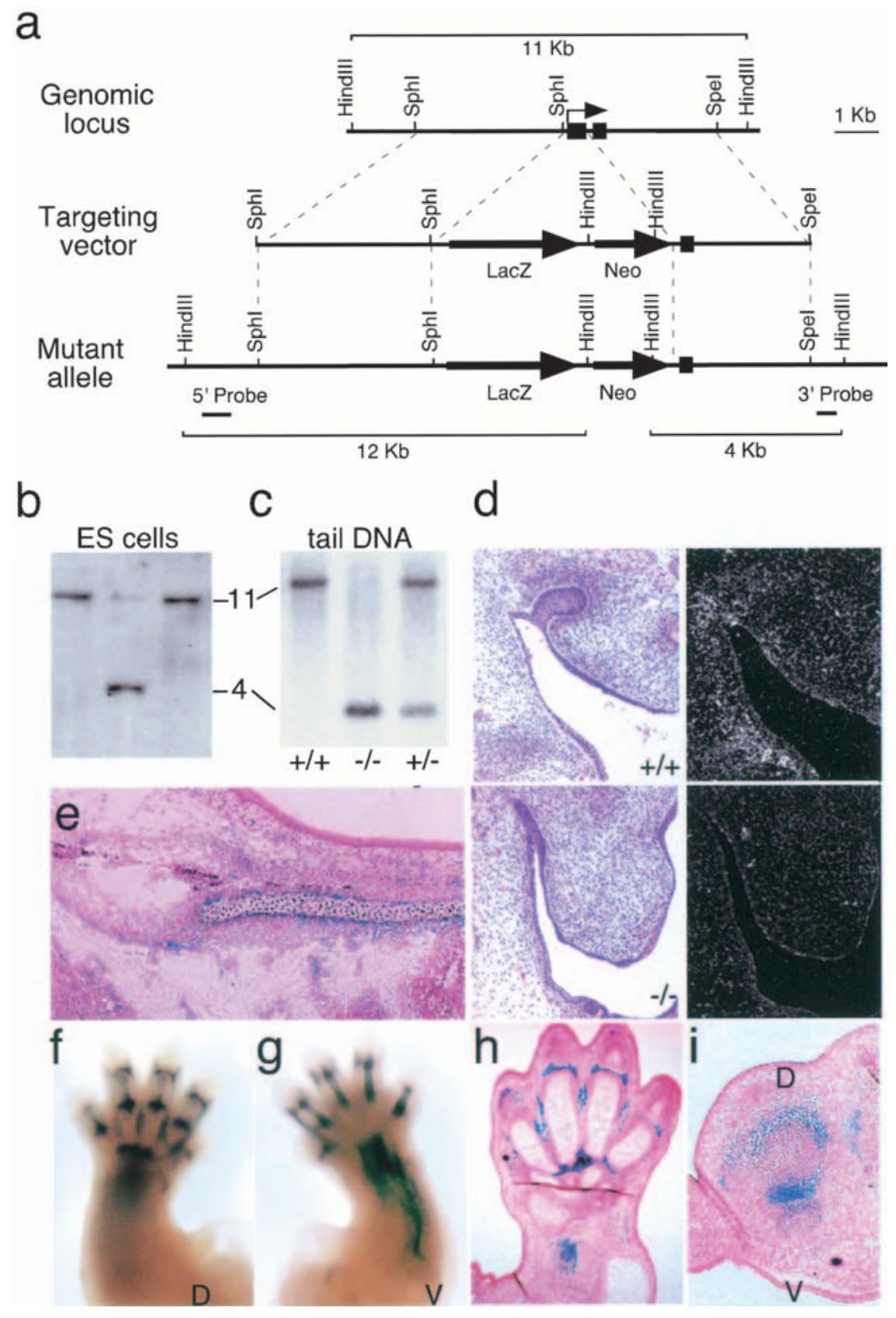

growth plate. These two processes are tightly regulated by several signaling pathways and must be coordinated to keep long bone growth in balance. The elongated proliferating and hypertrophic zones in $\mathrm{Fgfl}^{-8^{--}}$growth plates suggested that $F g f 18$ negatively regulates chondrocyte proliferation and/or differentiation, similar to that observed in mice lacking Fgfr3. To assess the effect of FGF18 on chondrocyte proliferation, pregnant females were injected with BrdU at E16.5. After two hours, embryos were collected and BrdU incorporation into chondrocytes in the proximal tibia and distal humerus was detected by immunohistochemistry. BrdU incorporation in proliferating chondrocytes of these two growth plates was increased by $14 \%(\mathrm{P}=0.001)$ and $24 \%(P<0.02)$, re- spectively. BrdU incorporation in the reserve zone of the proximal tibia was also increased by $36 \%(P<0.05)$ (Fig. $4 \mathrm{c}, \mathrm{d}_{\text {; }}$ Table 2). These data suggested that FGF18 either directly or indirectly inhibits chondrocyte proliferation during normal long bone growth and is consistent with FGF18 signaling to FGFR3 in proliferating chondrocytes.

The size of the hypertrophic zone is regulated by the rate of chondrocyte differentiation and chondrocyte apoptosis. Apoptotic chondrocytes are localized to a narrow band of cells in the hypertrophic chondrocyte-trabecular bone interface. No significant differences in TUNEL labeling were observed in $\mathrm{Fg} f 18^{-/-}$and wild-type control mice (data not shown). This suggested that chondrocyte apoptosis was unlikely to cause hypertrophic 
a

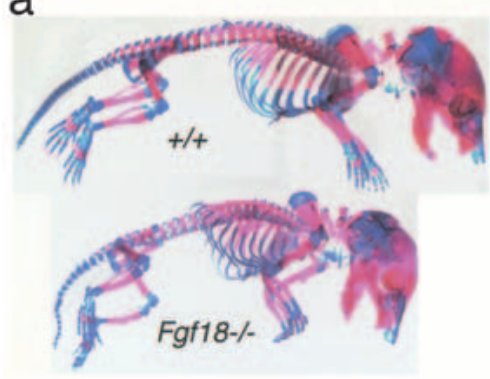

b

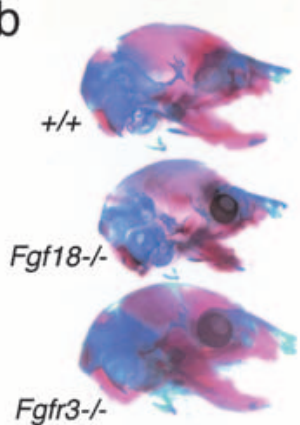

C

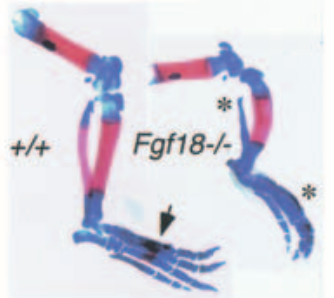

e

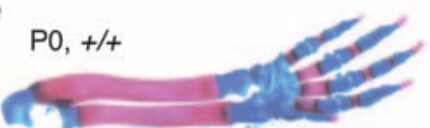

P0, Fgf18-/

g

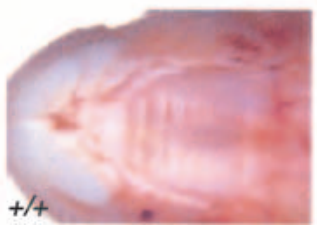

$\mathrm{d}$

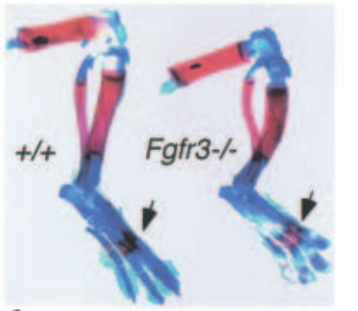

f

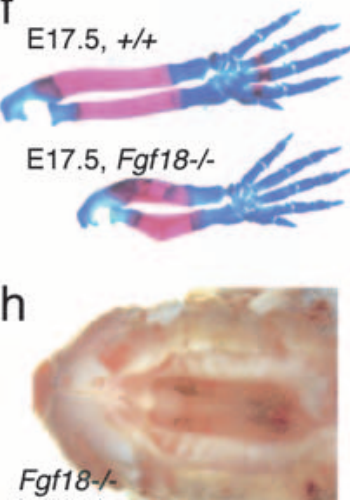

Figure 3. Morphological analysis of the skeletal phenotype in Fgf1 $8^{-/-}$mice. (a) Alizarin red- and alcian blue-stained skeletal preparations of neonatal (P0) mice. The $\mathrm{Fgf1} \mathrm{8}^{-/-}$skeleton is shown below and a wild-type littermate is shown above. Note the deformed ribs and smaller thoracic cavity in Fgf $18^{-/-}$mice. (b) Alizarin red- and alcian blue-stained skull from an E17.5 wild-type littermate (upper), an $\mathrm{Fgfl}^{-8^{--}}$embryo (middle), and an Fgfr $3^{-1-}$ embryo (lower), showing decreased growth of cranial bones in the $F g f 18^{-/-}$but not in the $\mathrm{Fgfr}^{-/-}$ skull. $(c, d)$ Higher-magnification view of the hind limbs from an E17.5 $\mathrm{Fgf18^{-/- }}$ embryo $(\mathrm{c})$ and $\mathrm{Fgfr3}^{-/-}$embryo $(d)$. Each panel also shows a wild-type littermate control. (*) Indicates a noticeable defect in $\mathrm{Fg} f 18^{-/-}$mice. The arrow indicates the ossification zone in the metatarsal bones. $(e, f)$ Forelimbs from P0 $(e)$ and E17.5 $(f)$ embryos showing delayed ossification in $\mathrm{Fgfl}_{18^{-/-}}$mice. Note that the P0 $\mathrm{Fgf18^{-/ }}$ limb looks similar to the E17.5 wild-type limb. $(g, h)$ Palate morphology from a wild-type littermate $(g)$ and a neonatal Fgf $18^{-/}$mouse (h). Note the complete cleft palate in the Fgf18 $8^{-/-}$mouse.

zone elongation in $\mathrm{Fg} f 18^{-/-}$mice. Hypertrophic chondrocytes were examined for type X collagen expression, a specific differentiation marker for all hypertrophic chondrocytes. In situ hybridization showed an expanded domain of type $\mathrm{X}$ collagen expression corresponding to the expanded hypertrophic zone of the $\mathrm{Fgfl}^{-/-}$

growth plate (Fig. 4e,f). Furthermore, the expression level of type X collagen appeared to be increased. This suggested that more extracellular matrix was produced by Fgf18 ${ }^{-/-}$hypertrophic chondrocytes and may reflect increased chondrocyte differentiation and increased metabolic activity.

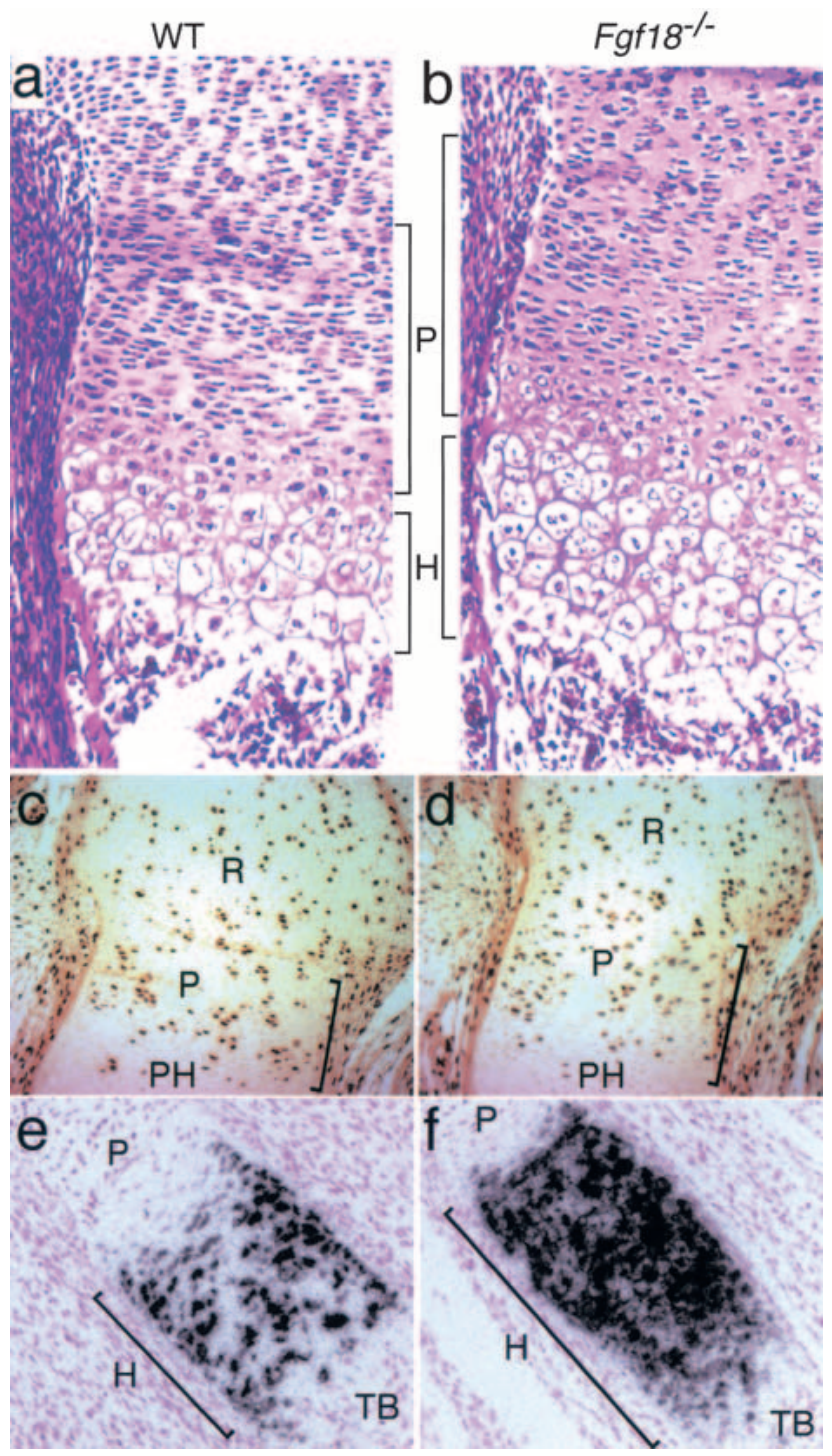

Figure 4. Histological analysis and identification of proliferating and hypertrophic chondrocytes using BrdU immunohistochemistry and type X collagen in situ hybridization. $(a, b)$ Hematoxylin and eosin-stained section of the distal femur from an E16.5 wild-type embryo $(a)$ and an $F g f 18^{-1-}$ embryo (b). Note the increased height of the $\mathrm{Fgf18} \mathrm{8}^{-/-}$proliferating and hypertrophic zones relative to that of the control. $(c, d)$ Immunohistochemical detection of BrdU-labeled chondrocytes in the epiphyseal growth plate of the distal femur from an E16.5 wild-type embryo $(c)$ and an Fgf18 $8^{-/-}$embryo $(d)$. $(e, f)$ Type X collagen expression in the distal fibula growth plate of an E18.5 wild-type littermate $(e)$ and $F g f 18^{-/-}$mouse $(f)$. (R) Reserve chondrocytes; $(\mathrm{P})$ proliferating chondrocytes; $(\mathrm{PH})$ prehypertrophic chondrocytes; $(\mathrm{H})$ hypertrophic chondrocytes; (TB) trabecular bone. 
Liu et al.

Table 1. Bone morphometric data

\begin{tabular}{|c|c|c|c|c|c|c|}
\hline Age & Growth plate ${ }^{a}$ & Genotype & $\mathrm{N}^{\mathrm{b}}$ & $\begin{array}{l}\text { Mean length } \\
(\mathrm{mm})^{\mathrm{c}}\end{array}$ & $\begin{array}{l}\text { Length } \\
\% \text { control }\end{array}$ & $P$ value \\
\hline \multirow[t]{4}{*}{ E16.5 } & \multirow[t]{2}{*}{ Distal femur HC } & $+/+$ & 4 & $0.30 \pm 0.01$ & \multirow{3}{*}{160} & \multirow{3}{*}{$<0.005$} \\
\hline & & $-1-$ & 4 & $0.48 \pm 0.08$ & & \\
\hline & \multirow[t]{2}{*}{ Distal femur PC } & $+1+$ & 4 & $0.47 \pm 0.02$ & & \\
\hline & & $-1-$ & 4 & $0.54 \pm 0.04$ & 114 & $<0.02$ \\
\hline \multirow[t]{4}{*}{ E18.5 } & \multirow[t]{2}{*}{ Distal femur HC } & $+/+$ & 4 & $0.24 \pm 0.02$ & \multirow{3}{*}{137} & \multirow{3}{*}{$<0.01$} \\
\hline & & $-1-$ & 4 & $0.33 \pm 0.04$ & & \\
\hline & \multirow{2}{*}{ Distal femur PC } & $+/+$ & 4 & $0.43 \pm 0.04$ & & \\
\hline & & $-1-$ & 4 & $0.46 \pm 0.03$ & 108 & 0.4 \\
\hline
\end{tabular}

a(PC) Proliferating chondrocyte zone; (HC) hypertrophic chondrocyte zone.

${ }^{b}$ Number of animals examined.

${ }^{\mathrm{c}}$ Mean length was determined with Zeiss Axio Vision 3.0 software.

\section{Fgf18 inhibits Ihh signaling}

Chondrogenesis requires a well-coordinated transition from proliferating to hypertrophic chondrocytes. Ihh stimulates chondrocyte proliferation and delays the transition from proliferation to hypertrophy. In $\mathrm{Ihh}^{-/-}$ mice, hypertrophic chondrocytes predominate in the growth plate (St-Jacques et al. 1999; Karp et al. 2000). The defective chondrogenesis in $\mathrm{Fgfl}^{-/-}$mice suggested that Fgf18 might interact with Ihh signaling. To assess the consequence of loss of Fgf18 on Ihh expression and signaling, the expression of Ihh and its receptor, patched, was examined in the growth plates of both wild-type and $\mathrm{Fgf18^{-/- }}$ mice.

Consistent with previous reports, expression of $I h h$ was restricted to prehypertrophic and proximal hypertrophic chondrocytes in both wild-type and $F g f 18^{-/-}$ mice (Fig. 5a-d). However, the intensity of the Ihh signal was significantly stronger in $F g f 18^{-/-}$growth plates compared to wild-type littermates. patched is expressed in proliferating chondrocytes, perichondrium, and the cartilage-bone interface (St-Jacques et al. 1999). The expression of patched is induced by Hedgehog signaling, and therefore the level of patched expression is a measure of the strength of the Hedgehog signal (Chen and Struhl 1996; Ingham 1998). Expression of patched was detected in the proliferating chondrocytes, perichondrium, and the cartilage-bone interface in both wild-type and $\mathrm{Fgfl} \mathrm{8}^{-/-}$mice (Fig. 5e-h). The expression of patched was significantly increased in the prolifer- ating chondrocyte region of $\mathrm{Fg} f 18^{-/-}$growth plates. However, the expression level of patched in the perichondrium and the cartilage-bone interface showed no significant differences between wild-type and the $\mathrm{Fg} / 18^{-/-}$ growth plates. These data support a model in which Fgf18 regulates chondrogenesis in part by inhibiting IHH signaling in prehypertrophic and proximal hypertrophic chondrocytes.

\section{Fgf18 promotes osteogenesis}

The phenotypic similarities between $\mathrm{Fg} 18^{-/-}$and $\mathrm{Fgfr}^{-1-}$ mice strongly suggest that FGF18 acts through FGFR3 to inhibit chondrocyte proliferation, differentiation, and IHH signaling. However, there are also significant differences. Close comparison of skeletal preparations from $\mathrm{Fgfl}^{-/-}$mice and $\mathrm{Fgfr} \mathrm{S}^{-/-}$mice clearly demonstrated a delayed ossification in $\mathrm{Fg} f 18^{-/-}$mice, which was not observed in $\mathrm{Fgfr}^{-/-}$mice (Fig. 3b-d; data not shown). This raises the possibility that FGF18 may also signal through other FGFRs to regulate osteogenesis and/ or osteoblast function.

To study the detailed molecular mechanism by which FGF18 normally regulates osteogenesis, we examined the expression of preosteogenic and osteogenic markers. Osteopontin $(\mathrm{Op})$ and osteocalcin $(\mathrm{Oc})$ are expressed in mature osteoblasts (Rodan and Noda 1991). At E15.5, expression of $O p$ was significantly decreased in the humerus of $\mathrm{Fgfl}^{-/-}$mice compared to littermate control

Table 2. Proliferation index for growth plate chondrocytes

\begin{tabular}{|c|c|c|c|c|c|c|}
\hline Age & Growth plate ${ }^{a}$ & Genotype & $\mathrm{N}^{\mathrm{b}}$ & BrdU+ $+0.01 \mathrm{~mm}^{2}$ & $\begin{array}{c}\text { Proliferation } \\
\% \text { control }\end{array}$ & $P$ value \\
\hline \multirow{6}{*}{ E16.5 } & \multirow{2}{*}{ Distal humerus PC } & $+/+$ & 2 & $1.82 \pm 0.04$ & \multirow{3}{*}{124} & \multirow{3}{*}{$<0.02$} \\
\hline & & $-1-$ & 2 & $2.25 \pm 0.07$ & & \\
\hline & \multirow[t]{2}{*}{ Proximal tibia PC } & $+/+$ & 4 & $2.38 \pm 0.05$ & & \\
\hline & & $-1-$ & 3 & $2.71 \pm 0.08$ & \multirow[t]{2}{*}{114} & \multirow[t]{2}{*}{0.001} \\
\hline & \multirow[t]{2}{*}{ Proximal tibia RC } & $+/+$ & 3 & $2.38 \pm 0.3$ & & \\
\hline & & $-1-$ & 3 & $3.64 \pm 0.5$ & 136 & $<0.05$ \\
\hline
\end{tabular}

${ }^{a}(\mathrm{PC})$ Proliferating chondrocyte zone; $(\mathrm{RC})$ reserve chondrocyte zone.

${ }^{b}$ Number of animals examined. 


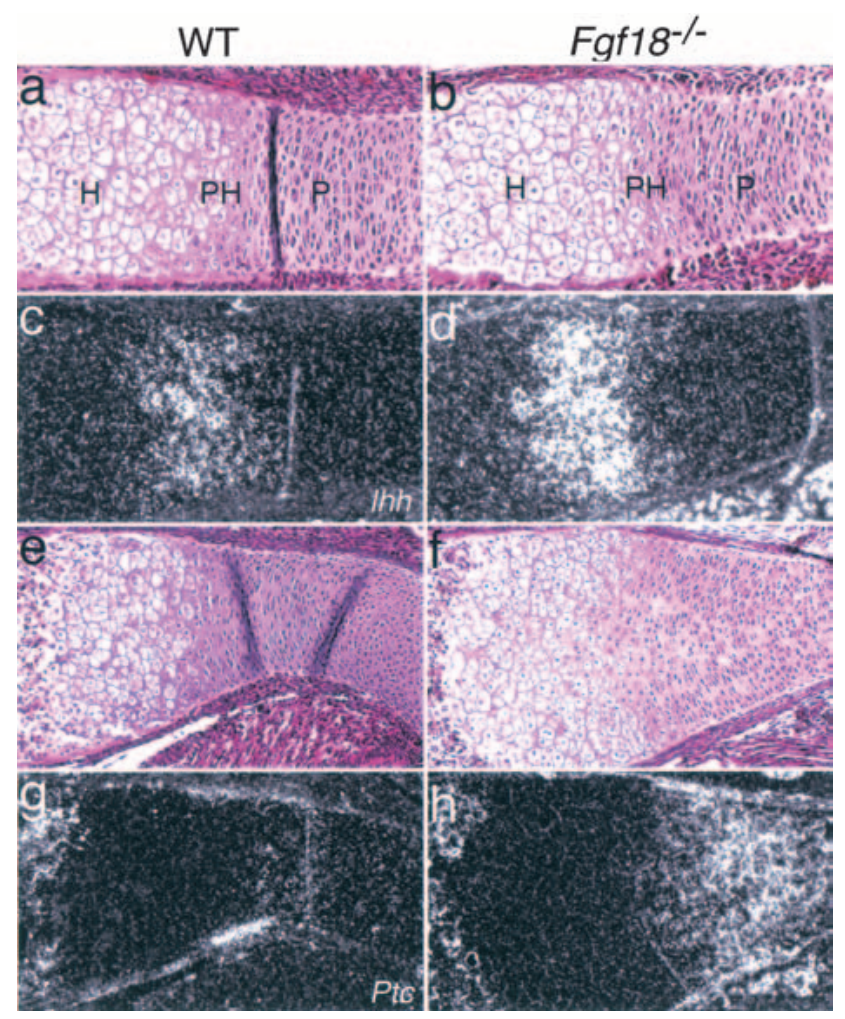

Figure 5. In situ detection of Ihh and patched in the developing growth plate. $(a-d)$ Ihh expression in the distal fibula growth plate of an E16.5 wild-type $(a, c)$ and $F g f 18^{-/-}(b, d)$ mouse. $(e-h)$ patched expression in the distal humerus growth plate of an E16.5 wild-type $(e, g)$ and $F g f 18^{-/-}(f, h)$ mouse. Brightfield $(a, b, e, f)$ and darkfield $(c, d, g, h)$ images are shown. (P) Proliferating chondrocytes; $(\mathrm{PH})$ prehypertrophic chondrocytes; $(\mathrm{H})$ hypertrophic chondrocytes.

mice (Fig. 6c,d). Oc expression was similarly down-regulated in $\mathrm{Fgf1} \mathrm{8}^{-/-}$mice at this stage (data not shown). Cbfa1 is one of the earliest osteogenic markers and is expressed in perichondral/periosteal mesenchymal cells committed to become osteoblasts. CBFA1 is required for the specification of the osteogenic lineage (Ducy et al. 1997; Karsenty et al. 1999). Cbfa1 expression was similar in the perichondrium/periosteum and endosteum of both wild-type and Fgf18 $18^{-/}$mice. However, the expression level of Cbfa1 in trabecular bone was greatly decreased (Fig. 6e,f). These data demonstrated that osteoprogenitor cells were present in the perichondrium/periosteum but functional osteoblasts were deficient in the trabecular region, suggesting that FGF18 function is required in the process of osteoblast maturation/proliferation. Alternatively, FGF18 could regulate the influx of osteoblasts into the trabecular region by regulating the expression of angiogenic factors or molecules required for the remodeling of the extracellular matrix in the hypertrophic chondrocyte zone. To test these possibilities, we examined the expression of vascular endothelial growth factor (Vegf) and matrix metalloproteinase $(M m p 9)$. No significant differences in Vegf and Mmp9 expression were observed in wild-type and $\mathrm{Fgf18^{-/ }}$ mice
(Fig. 6g,h; data not shown). These data suggested that FGF18 may have a more direct effect on osteoblast development in trabecular bone or mediate the influx of osteoblasts by other means.

\section{Discussion}

Mutations in FGF receptors demonstrate that FGF signaling is intimately involved in the regulation of bone development and growth. However, the physiologic FGF ligand(s) that must signal to FGFRs in developing bone remain elusive. Here we show a skeletal phenotype in mice lacking Fgf18, demonstrating that FGF18 is an important mediator of skeletal development. Comparison of the growth plate of $\mathrm{Fgf18^{-/- }}$ mice with that of $\mathrm{Fgfr3}^{-/-}$ mice shows several similar features, which strongly suggests that FGF18 is a physiologic ligand for FGFR3. How-

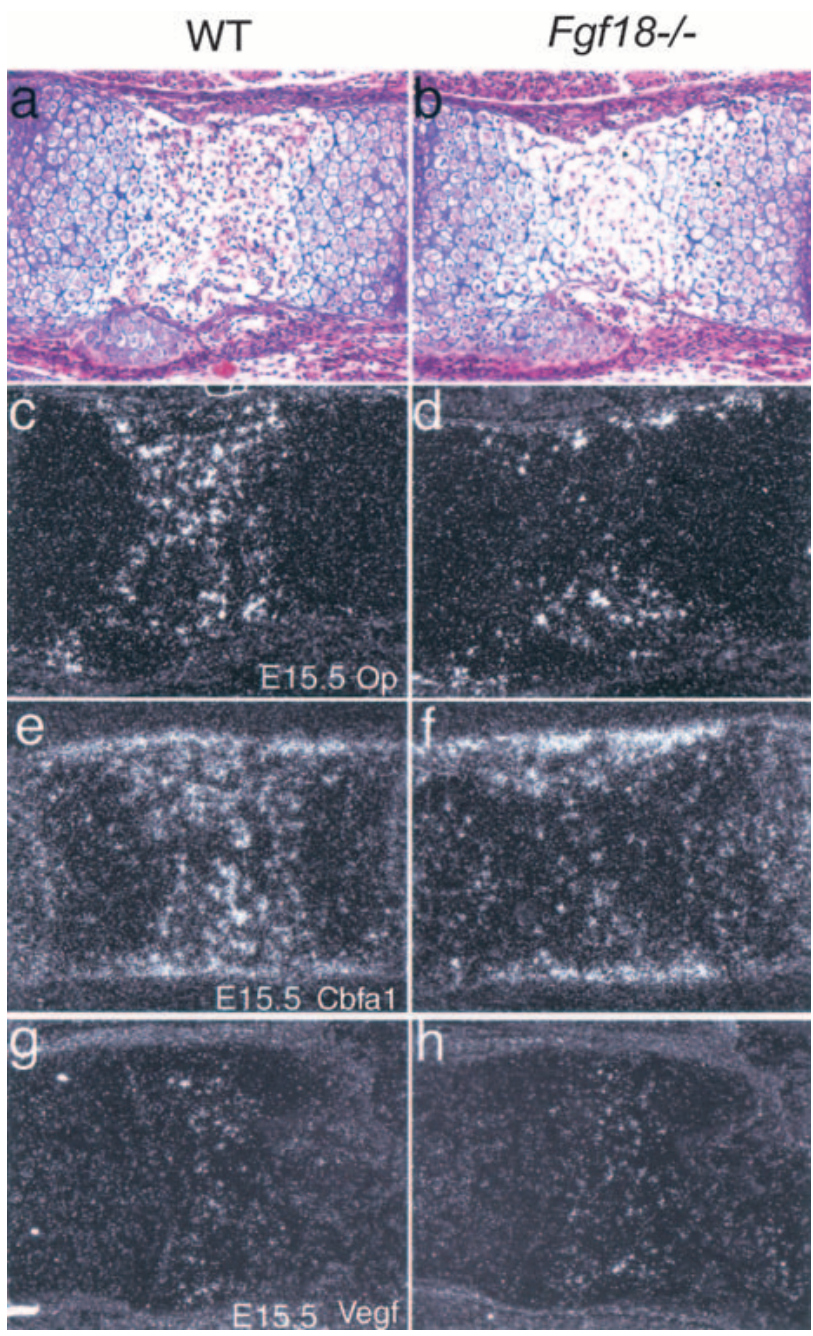

Figure 6. In situ detection of osteopontin, Cbfa1, and Vegf in the developing growth plate of the humerus at E15.5. $(a, b)$ Brightfield images. $(c-h)$ Darkfield images. $(c, d)$ Op expression. $(e, f) C b f a 1$ expression. $(g, h)$ Vegf expression. $(a, c, e, g)$ Sections from wild-type littermates. $(b, d, f, h)$ Sections from $F g f 18^{-/-}$ mice. 
ever, phenotypic differences demonstrate that FGF18 must also signal to other FGFRs in developing bone.

Although FGFs are generally considered to be mitogens for a variety of cell types, several studies have shown that signaling through FGFR3 inhibits chondrocyte proliferation in vivo (Colvin et al. 1996; Naski et al. 1998; Sahni et al. 1999). Mice lacking Fgfr3 exhibit an increase in the number of proliferating chondrocytes and

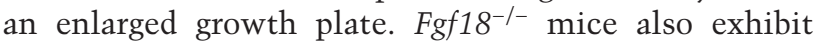
similar features. Recent data demonstrate that this inhibition may be due to a direct effect on the chondrocyte (Sahni et al. 1999; Henderson et al. 2000) and may be independent of the specific FGFR tyrosine kinase domain expressed (Wang et al. 2001). The expression of Fgf18 in the perichondrium, adjacent to Fgfr3-expressing proliferating chondrocytes, is consistent with our hypothesis that FGF18 acts as a paracrine factor signaling through FGFR3 to inhibit chondrocyte proliferation (Fig. 7).

In $\mathrm{Fg} f 18^{-/-}$mice and $\mathrm{Fgfr} \mathrm{3}^{-/-}$mice, both the proliferating zone and hypertrophic zone were expanded. Gainand loss-of-function experiments with FGFR3 showed that in addition to inhibiting chondrocyte proliferation, FGFR3 also inhibited chondrocyte differentiation (Colvin et al. 1996; Deng et al. 1996; Naski et al. 1998). In $\mathrm{Fgf18^{-/- }}$ mice, chondrocyte differentiation was assessed by examining the expression of the hypertrophic chondrocyte differentiation marker, type X collagen, and the extent of apoptosis in hypertrophic chondrocytes. The increased expression of type $\mathrm{X}$ collagen and the similar amount of apoptosis in distal hypertrophic chondrocytes was again consistent with the phenotype of $\mathrm{Fgfr}^{-/-}$mice and suggests that the most likely mechanism for hypertrophic zone elongation is increased chondrocyte differentiation. Increased differentiation could be a direct effect of decreased signaling through FGFR3 in proliferating and prehypertrophic chondrocytes, it could be due to changes in signaling through other pathways (see below), or it could be a consequence of an increased pool of proliferating chondrocytes.

The perichondrium that surrounds developing cartilage has been shown to transmit signals that negatively regulate both chondrocyte proliferation and differentiation in in vitro perichondrium-free cultures of either chick or mouse bones (Long and Linsenmayer 1998; Haaijman et al. 1999; Alvarez et al. 2001). However, the molecular identity of this signal has not been identified. The expression of Fgf18 in the perichondrium, the observed increased BrdU incorporation in the proliferating chondrocyte zone, and the increased type X collagen expression in $\mathrm{Fgf1} 8^{-/-}$mice suggests that FGF18 is a good candidate for this signal.

In addition to a direct effect on proliferation and differentiation mediated through FGFRs, FGF signaling

Figure 7. Model for Fgf18 regulation of long bone growth. In a linear model of chondrogenesis, chondrocytes sequentially develop through reserve $(\mathrm{R})$, proliferating $(\mathrm{P})$, prehypertrophic $(\mathrm{PH})$, and hypertrophic $(\mathrm{H})$ stages. The rectangles indicate the relative expression domains of signaling molecules in the growth plate. Previous studies show that FGFR3 inhibits (1) chondrocyte proliferation, (2) chondrocyte differentiation, and (3) Ihh expression in prehypertrophic chondrocytes (Naski et al. 1998). Fgf18 is expressed in the perichondrium and is proposed to activate FGFR3 signaling in proliferating and prehypertrophic chondrocytes (green arrow). FGF18 may also signal to FGFR1 in hypertrophic chondrocytes and FGFR2 in the perichondrium and in trabecular bone. Decreased IHH signaling through Patched (PTC) and Smoothened (SMO) results in decreased PTHrP expression in the periarticular perichondrium and signaling to the PTHrP receptor (PTHrP-R) in prehypertrophic chondrocytes. PTHrP-R signaling delays chondrocyte maturation. FGF18 could inhibit chondrocyte proliferation either directly through the action of FGFR3 in proliferating chondrocytes or indirectly by repressing the IhhPatched-PTHrP signaling pathway. Contrary to its function in chondrogenesis, FGF18 positively regulates osteogenesis. In a linear model of osteogenesis, mesenchymal cells (MC) develop into osteogenic pro-

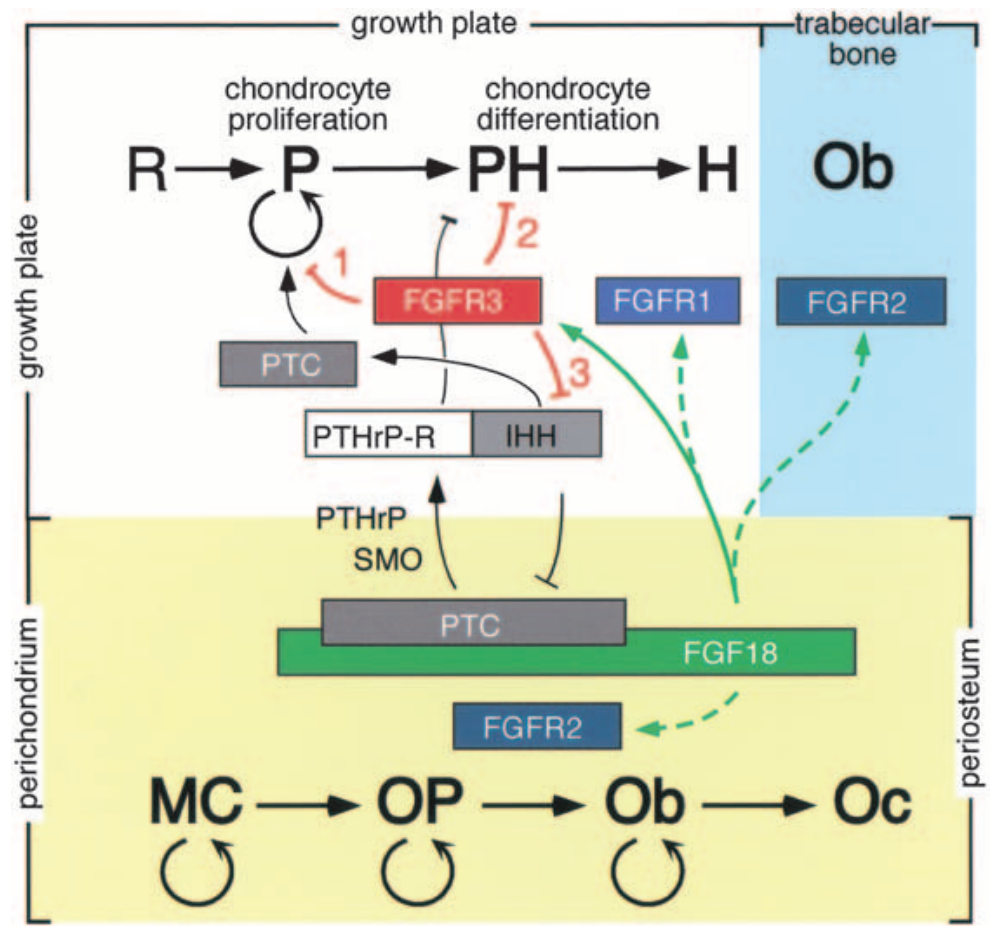
genitor cells (OP), which express Cbfa1. OP cells then differentiate into mature osteoblasts (OB) which eventually become entrapped in bone as osteocytes (OC). In cortical bone, FGF18 promotes osteoblast maturation/proliferation, but has no effect on the formation of the osteoprogenitor cell population. This suggests that FGF signaling affects differentiation of the committed osteoprogenitor cell. The delayed formation of trabecular bone suggests that FGF18 signals directly through FGFR1 or indirectly through other factors to regulate ossification of hypertrophic chondrocytes. FGF18 signaling to FGFR3 in proliferating chondrocytes and potentially to FGFR2 in the perichondrium/periosteum or FGFR1 in hypertrophic chondrocytes places FGF18 in a position to coordinate rates of growth and differentiation in developing bone. 
may have an indirect effect mediated by other signaling molecules expressed in developing bone. In both Fgf18 and Fgfr3 knockout mice, Ihh expression is increased, and in mouse models for achondroplasia, Ihh expression is suppressed (Naski et al. 1998; Chen et al. 2001). Thus FGF18 and FGFR3 are negative regulators of IHH signaling. $\mathrm{Ihh}^{-1-}$ embryos show a smaller zone of proliferating chondrocytes with reduced BrdU incorporation (StJacques et al. 1999). These data suggest that one function of IHH signaling is to stimulate chondrocyte proliferation. It is possible that the suppression of chondrocyte proliferation by FGF18 is mediated indirectly by suppressing IHH signaling. Conversely, IHH could stimulate chondrocyte proliferation by inhibiting FGF18. The increased expression of $I h h$ and its receptor, patched, in the growth plate of $\mathrm{Fgf}_{18^{-/-}}$mice is most consistent with the former possibility.

Ihh, produced by prehypertrophic chondrocytes, induces the expression of PTHrP in the periarticular perichondrium (Lanske et al. 1996; Vortkamp et al. 1996). PTHrP acts through PTHrP-R in proliferating chondrocytes to delay their transition from proliferation to hypertrophy and thus reduces the number of cells expressing Ihh. In this way, the rate of chondrocytes leaving the proliferation cycle is precisely controlled (Lanske et al. 1996; Vortkamp et al. 1996). The data presented here provide evidence that $I h h$ is also regulated by a second mechanism in which FGF18 signals from the perichondrium through FGFR3 in the proliferating/prehypertrophic chondrocytes to suppress Ihh expression (Fig. 7). These data also identify FGF18 as a perichondrial regulator of endochondral bone growth. A similar role has been identified for PTHrP (Karaplis et al. 1994; Lanske et al. 1996). The next important step will be to determine how feedback mechanisms regulate the expression of Fgf18.

Thus far we have considered phenotypic similarities between $\mathrm{Fgfl}^{-8^{--}}$mice and $\mathrm{Fgfr} \mathrm{S}^{-/-}$mice. However, the formation and extent of ossification is delayed in $\mathrm{Fgf18^{-/- }}$ mice but not in $\mathrm{Fgfr} 3^{-/-}$mice. This raises the possibility that FGF18 may also signal through FGFR1 in hypertrophic chondrocytes and FGFR2 in the perichondrium/periosteum to regulate osteogenesis (Fig. 7). The normal level of $C b f a 1$ expression in the perichondrium/ periosteum of $F g f 18^{-/-}$mice suggests the presence of normal numbers of osteoprogenitor cells. These data demonstrate that FGF18 most likely functions to promote osteoblast maturation/proliferation (observed delayed ossification of cortical bone), but is not required for the early specification of the osteogenic cell lineage (Fig. 7). However, the expression of $C b f a 1, O p$, and $O c$ is greatly reduced in the ossification zone giving rise to trabecular bone, which demonstrates a deficiency of functional osteoblasts in this region. This deficiency may be due to a defect in the ability of osteoblast progenitors to populate the distal hypertrophic zone or a defect or delay in vascular invasion of the distal hypertrophic zone. The normal expression of VEGF and MMP9 suggests that at least some of the signals required for the ossification process are intact in $\mathrm{Fgfl}^{-/-}$mice. Our data are therefore most consistent with FGF18 directly regulating osteogenesis or vascular invasion of the distal hypertrophic zone.

Experiments in which Fgfr2 has been conditionally knocked out in developing bone demonstrates that FGFR2 positively regulates bone growth $(\mathrm{K}$. Yu and D. Ornitz, unpubl.). FGFR2 could thus be an autocrine/juxtocrine receptor to transduce an FGF18 signal in the perichondrium/periosteum. FGF18 expression is thus localized, both spatially and developmentally, in a position where it could coordinate both chondrogenesis in the growth plate and osteogenesis in cortical and trabecular bone (Fig. 7). The calvarial phenotype in $\mathrm{Fgfl}^{-{ }^{-/}}$mice also supports a model in which FGF18 signals through FGFR1 and/or FGFR2, because these are the predominant FGFRs expressed in developing calvarial bones (Iseki et al. 1999; Rice et al. 2000). Further experiments will be required to determine the extent of FGF18 signaling through other FGFRs.

\section{Materials and methods}

\section{Generation of Fgf18-targeted mice}

A 7.1-kb SphI-SpeI genomic clone containing exons 1 and 2 was used to construct the targeting vector. Exon 1 was deleted and replaced by a $7-\mathrm{kb}$ DNA fragment containing a $\beta$-galactosidase cassette followed by a neoselection cassette. The targeting construct was linearized with NotI prior to electroporation into RW-4 embryonic stem cells. Selected G418-resistant clones were screened by Southern blot analysis of HindIII-digested genomic DNA using both 5' and 3'-probes (Fig. 2a). Cells from one positive clone were injected into blastocysts of C57BL6/J mice and transferred into the uteri of pseudopregnant females. Chimeric males were mated with C57BL6/J females, and offspring were screened by Southern blot analysis of tail genomic DNA. Heterozygous littermates were mated to obtain homozygous animals (Fig. 2a-c).

\section{Skeletal preparations}

Skeletons were prepared as described previously (Colvin et al. 1996). For postnatal day 0 (P0) skeletal preparations, carcasses were skinned and eviscerated, and then soaked in acetone for $12-24 \mathrm{~h}$, cleared in $2 \% \mathrm{KOH}(12-24 \mathrm{~h})$, stained with alizarin red $\mathrm{S}$ and alcian blue (12-24 h), cleared in $1 \% \mathrm{KOH} / 20 \%$ glycerol, and stored in glycerol. For embryo skeleton preparations, fetuses were skinned and eviscerated, stained with alizarin red $\mathrm{S}$ and alcian blue (12-24 h), cleared in $1 \% \mathrm{KOH} / 20 \%$ glycerol, and stored in glycerol.

\section{Histological analysis}

Tissues were fixed in $4 \%$ paraformaldehyde/PBS or $10 \%$ formalin, decalcified if necessary in EDTA or Decalcifying Solution (Stephens Scientific), and embedded in paraffin. Sections were stained with hematoxylin and eosin (H\&E). Computer imaging using AxioVision 3.0 software (Zeiss) was used to calculate the length of proliferating and hypertrophic chondrocyte zones. Each length was measured three times along the midline of the corresponding growth plate in H\&E stained sections. Proliferating and hypertrophic zones were demarcated as shown in Figure 4 . The top of the brackets around the proliferating chondro- 
cyte zone were defined based on bone morphology; that is, the narrowest part of the growth plate.

\section{Analysis of cell proliferation}

Anti-BrdU immunohistochemistry was carried out as described (Naski et al. 1998) with minor modifications. Pregnant mice were injected intraperitoneally with $\mathrm{BrdU}(100 \mathrm{mg} / \mathrm{kg}) 1 \mathrm{~h}$ before sacrifice. Embryos were fixed in $4 \%$ paraformaldehyde at $4^{\circ} \mathrm{C}$ for $2 \mathrm{~h}$. BrdU was detected with an anti-BrdU antibody (Becton Dickinson Immunocytometry Systems) using the ABC kit (Vector Lab) according to the manufacturer's instructions. All of the BrdU-positive nuclei of reserve and columnar proliferating chondrocytes were counted and the area of the proliferating chondrocyte zone was measured using AxioVision 3.0 image software (Zeiss). The number of BrdU-positive nuclei per $0.01 \mathrm{~mm}^{2}$ area was calculated for $\mathrm{Fgfl}^{-/-}$and wild-type littermate embryos. At least three sections were counted for each embryo examined.

\section{In situ hybridization}

In situ hybridization was performed as described $(\mathrm{Xu}$ et al. 1999). The plasmids used for generating $P^{33}$-labeled riboprobes were generously provided by B. Olsen (Type X collagen), M. Scott (patched), A. McMahon (Ihh), K. Lee (Osteopontin), K. Nakashima (Cbfa1), and G. Karsenty (VEGF).

\section{Acknowledgments}

We thank Ling Li, Ed Spinaio, Heather Walker, and Craig Smith for their excellent technical help, Xiang Hua for microinjection, the Washington University Siteman Cancer Center Embryonic Stem Cell core facility for ES cell culture, and the MBP histology core facility. We also thank L. Sandell and R. Kopan for critically reading this manuscript. This work was supported by NIH grants HD39952, CA60673, DK52574, AR45254, the American Heart Association number 974-0221N, and a grant from Zymogenetics, Inc.

The publication costs of this article were defrayed in part by payment of page charges. This article must therefore be hereby marked "advertisement" in accordance with 18 USC section 1734 solely to indicate this fact.

\section{References}

Alvarez, J., Horton, J., Sohn, P., and Serra, R. 2001. The perichondrium plays an important role in mediating the effects of TGF- $\beta 1$ on endochondral bone formation. Dev. Dyn. 221: $311-321$.

Caplan, A.I. and Pechak, D.G. 1987. The cellular and molecular embryology of bone formation. In Bone and mineral research (ed. W.A. Peck), pp. 117-183. Elsevier Science Publishers, New York, NY.

Chen, L., Li, C., Qiao, W., Xu, X., and Deng, C. 2001. A Ser(365) $\rightarrow$ Cys mutation of fibroblast growth factor receptor 3 in mouse downregulates Ihh/PTHrP signals and causes severe achondroplasia. Hum. Mol. Genet. 10: 457-465.

Chen, Y. and Struhl, G. 1996. Dual roles for patched in sequestering and transducing Hedgehog. Cell 87: 553-563.

Colvin, J.S., Bohne, B.A., Harding, G.W., McEwen, D.G., and Ornitz, D.M. 1996. Skeletal overgrowth and deafness in mice lacking fibroblast growth factor receptor 3. Nat. Genet. 12: 390-397.

Colvin, J.S., Feldman, B., Nadeau, J.H., Goldfarb, M., and Or- nitz, D.M. 1999. Genomic organization and embryonic expression of the mouse fibroblast growth factor 9 gene. Dev. Dyn. 216: $72-88$.

Colvin, J.S., Green, R.P., Schmahl, J., Capel, B., and Ornitz, D.M. 2001a. Male-to-female sex reversal in mice lacking fibroblast growth factor 9. Cell 104: 875-889.

Colvin, J.S., White, A., Pratt, S.J., and Ornitz, D.M. 2001b. Lung hypoplasia and neonatal death in Fgf9-null mice identify this gene as an essential regulator of lung mesenchyme. Development 128: 2095-2106.

Deng, C., Wynshaw-Boris, A., Zhou, F., Kuo, A., and Leder, P. 1996. Fibroblast growth factor receptor 3 is a negative regulator of bone growth. Cell 84: 911-921.

Dono, R., Texido, G., Dussel, R., Ehmke, H., and Zeller, R. 1998. Impaired cerebral cortex development and blood pressure regulation in Fgf-2-deficient mice. EMBO J. 17: 42134225.

Ducy, P., Zhang, R., Geoffroy, V., Ridall, A.L., and Karsenty, G. 1997. Osf2/Cbfal: A transcriptional activator of osteoblast differentiation. Cell 89: 747-754.

Erlebacher, A., Filvaroff, E.H., Gitelman, S.E., and Derynck, R. 1995. Toward a molecular understanding of skeletal development. Cell 80: 371-378.

Gerber, H.P. and Ferrara, N. 2000. Angiogenesis and bone growth. Trends Cardiovasc. Med. 10: 223-228.

Gibson, G. 1998. Active role of chondrocyte apoptosis in endochondral ossification. Microsc. Res. Tech. 43: 191-204.

Haaijman, A., Karperien, M., Lanske, B., Hendriks, J., Lowik, C.W., Bronckers, A.L., and Burger, E.H. 1999. Inhibition of terminal chondrocyte differentiation by bone morphogenetic protein 7 (OP-1) in vitro depends on the periarticular region but is independent of parathyroid hormone-related peptide. Bone 25: 397-404.

Halford, M.M., Armes, J., Buchert, M., Meskenaite, V., Grail, D., Hibbs, M.L., Wilks, A.F., Farlie, P.G., Newgreen, D.F., Hovens, C.M., et al. 2000. Ryk-deficient mice exhibit craniofacial defects associated with perturbed Eph receptor crosstalk. Nat. Genet. 25: 414-418.

Hall, B.K. and Miyake, T. 1992. The membranous skeleton: The role of cell condensations in vertebrate skeletogenesis. Anat. Embryol. (Berl.) 186: 107-124.

Hall, B.K. and Miyake, T. 2000. All for one and one for all: Condensations and the initiation of skeletal development. BioEssays 22: 138-147.

Henderson, J.E., Naski, M.C., Aarts, M.M., Wang, D., Cheng, L., Goltzman, D., and Ornitz, D.M. 2000. Expression of FGFR3 with the G380R achondroplasia mutation inhibits proliferation and maturation of CFK2 chondrocytic cells. J. Bone Miner. Res. 15: 155-165.

Hill, D.J., Logan, A., Ong, M., De Sousa, D., and Gonzalez, A.M 1992. Basic fibroblast growth factor is synthesized and released by isolated ovine fetal growth plate chondrocytes: Potential role as an autocrine mitogen. Growth Factors 6: 277294.

Ingham, P.W. 1998. Transducing hedgehog: The story so far. EMBO J. 17: 3505-3511.

Iseki, S., Wilkie, A.O., and Morriss-Kay, G.M. 1999. Fgfr1 and Fgfr2 have distinct differentiation- and proliferation-related roles in the developing mouse skull vault. Development 126: $5611-5620$.

Johnson, D.E. and Williams, L.T. 1993. Structural and functional diversity in the FGF receptor multigene family. $A d v$. Cancer Res. 60: 1-41.

Karaplis, A.C., Luz, A., Glowacki, J., Bronson, R.T., Tybulewicz, V.L.J., Kronenbery, H.M., and Mulligan, R.C. 1994. Lethal skeletal dysplasia from targeted disruption of the parathy- 
roid hormone-related peptide gene. Genes \& Dev. 8: 277 289.

Karp, S.J., Schipani, E., St-Jacques, B., Hunzelman, J., Kronenberg, H., and McMahon, A.P. 2000. Indian hedgehog coordinates endochondral bone growth and morphogenesis via parathyroid hormone related-protein-dependent and -independent pathways. Development 127: 543-548.

Karsenty, G. 2001. Genetic control of skeletal development. Novartis Found. Symp. 232: 6-22.

Karsenty, G., Ducy, P., Starbuck, M., Priemel, M., Shen, J., Geoffroy, V., and Amling, M. 1999. Cbfal as a regulator of osteoblast differentiation and function. Bone 25: 107-108.

Lanske, B., Karaplis, A.C., Lee, K., Luz, A., Vortkamp, A., Pirro, A., Karperien, M., Defize, L.H.K., Ho, C., Mulligan, R.C., et al. 1996. PTH/PTHrP receptor in early development and indian hedgehog-regulated bone growth. Science 273: 663-666.

Lewandoski, M., Sun, X., and Martin, G.R. 2000. Fgf8 signalling from the AER is essential for normal limb development. Nat. Genet. 26: 460-463.

Long, F. and Linsenmayer, T.F. 1998. Regulation of growth region cartilage proliferation and differentiation by perichondrium. Development 125: 1067-1073.

Luan, Y., Praul, C.A., Gay, C.V., and Leach, Jr., R.M. 1996. Basic fibroblast growth factor: An autocrine growth factor for epiphyseal growth plate chondrocytes. J. Cell. Biochem. 62: $372-382$.

Martin, G.R. 1998. The roles of FGFs in the early development of vertebrate limbs. Genes \& Dev. 12: 1571-1586.

Min, H., Danilenko, D.M., Scully, S.A., Bolon, B., Ring, B.D., Tarpley, J.E., DeRose, M., and Simonet, W.S. 1998. Fgf-10 is required for both limb and lung development and exhibits striking functional similarity to Drosophila branchless. Genes \& Dev. 12: 3156-3161.

Moon, A.M. and Capecchi, M.R. 2000. Fgf8 is required for outgrowth and patterning of the limbs. Nat. Genet. 26: 455-459.

Moon, A.M., Boulet, A.M., and Capecchi, M.R. 2000. Normal limb development in conditional mutants of Fgf4. Development 127: 989-996.

Muenke, M. and Schell, U. 1995. Fibroblast-growth-factor receptor mutations in human skeletal disorders. Trends Genet. 11: 308-313.

Naski, M.C. and Ornitz, D.M. 1998. FGF signaling in skeletal development. Front. Biosci. 3: D781-D794.

Naski, M.C., Colvin, J.S., Coffin, J.D., and Ornitz, D.M. 1998. Repression of hedgehog signaling and BMP4 expression in growth plate cartilage by fibroblast growth factor receptor 3 . Development 125: 4977-4988.

Ohuchi, H., Nakagawa, T., Yamamoto, A., Araga, A., Ohata, T., Ishimaru, Y., Yoshioka, H., Kuwana, T., Nohno, T., Yamasaki, M., et al. 1997. The mesenchymal factor, FGF10, initiates and maintains the outgrowth of the chick limb bud through interaction with FGF8, an apical ectodermal factor. Development 124: 2235-2244.

Ornitz, D.M. 2001. Regulation of chondrocyte growth and differentiation by fibroblast growth factor receptor 3. Novartis Found. Symp. 232: 63-80, 272-282.

Ornitz, D.M. and Itoh, N. 2001. Fibroblast growth factors. Genome Biol. 2: 3005.

Ornitz, D.M., Xu, J., Colvin, J.S., McEwen, D.G., MacArthur, C.A., Coulier, F., Gao, G., and Goldfarb, M. 1996. Receptor specificity of the fibroblast growth factor family. J. Biol. Chem. 271: 15292-15297.

Orr-Urtreger, A., Givol, D., Yayon, A., Yarden, Y., and Lonai, P. 1991. Developmental expression of two murine fibroblast growth factor receptors, $f l g$ and bek. Development 113: $1419-1434$
Ortega, S., Ittmann, M., Tsang, S.H., Ehrlich, M., and Basilico C. 1998. Neuronal defects and delayed wound healing in mice lacking fibroblast growth factor 2. Proc. Natl. Acad. Sci. 95: 5672-5677.

Peters, H., Neubuser, A., Kratochwil, K., and Balling, R. 1998. Pax9-deficient mice lack pharyngeal pouch derivatives and teeth and exhibit craniofacial and limb abnormalities. Genes \& Dev. 12: 2735-2747.

Peters, K.G., Werner, S., Chen, G., and Williams, L.T. 1992. Two FGF receptor genes are differentially expressed in epithelial and mesenchymal tissues during limb formation and organogenesis in the mouse. Development 114: 233-243.

Peters, K., Ornitz, D.M., Werner, S., and Williams, L. 1993. Unique expression pattern of the FGF receptor 3 gene during mouse organogenesis. Dev. Biol. 155: 423-430.

Rice, D.P.C., Aberg, T., Chan, Y.S., Tang, Z.Q., Kettunen, P.J., Pakarinen, L., Maxson, R.E., and Thesleff, I. 2000. Integration of FGF and TWIST in calvarial bone and suture development. Development 127: 1845-1855.

Rodan, G.A. and Noda, M. 1991. Gene expression in osteoblastic cells. Crit. Rev. Eukaryot. Gene Expr. 1: 85-98.

Sahni, M., Ambrosetti, D.C., Mansukhani, A., Gertner, R., Levy, D., and Basilico, C. 1999. FGF signaling inhibits chondrocyte proliferation and regulates bone development through the STAT-1 pathway. Genes \& Dev. 13: 1361-1366.

St-Jacques, B., Hammerschmidt, M., and McMahon, A.P. 1999. Indian hedgehog signaling regulates proliferation and differentiation of chondrocytes and is essential for bone formation. Genes \& Dev. 13: 2072-2086.

Sun, X., Lewandoski, M., Meyers, E.N., Liu, Y.H., Maxson, Jr., R.E., and Martin, G.R. 2000. Conditional inactivation of Fgf4 reveals complexity of signalling during limb bud development. Nat. Genet. 25: 83-86.

Twal, W.O., Vasilatos-Younken, R., Gay, C.V., and Leach, Jr., R.M. 1994. Isolation and localization of basic fibroblast growth factor-immunoreactive substance in the epiphyseal growth plate. J. Bone Miner. Res. 9: 1737-1744.

Vortkamp, A., Lee, K., Lanske, B., Segre, G.V., Kronenberg, H.M., and Tabin, C.J. 1996. Regulation of rate of cartilage differentiation by indian hedgehog and PTH-related protein. Science 273: 613-622.

Wang, Q., Green, R.P., Zhao, G., and Ornitz, D.M. 2001. Differential regulation of endochondral bone growth and joint development by FGFR1 and FGFR3 tyrosine kinase domains. Development 128: 3867-3876.

Xu, J., Lawshe, A., MacArthur, C.A., and Ornitz, D.M. 1999 Genomic structure, mapping, activity and expression of fibroblast growth factor 17. Mech. Dev. 83: 165-178.

Xu, J.S., Liu, Z.H., and Ornitz, D.M. 2000. Temporal and spatial gradients of Fgf8 and Fgf17 regulate proliferation and differentiation of midline cerebellar structures. Development 127: $1833-1843$

Zhou, M., Sutliff, R.L., Paul, R.J., Lorenz, J.N., Hoying, J.B., Haudenschild, C.C., Yin, M., Coffin, J.D., Kong, L., Kranias, E.G., et al. 1998. Fibroblast growth factor 2 control of vascular tone. Nat. Med. 4: 201-207. 


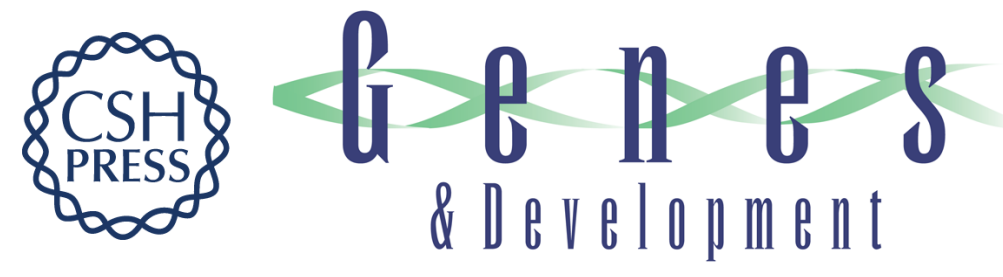

\section{Coordination of chondrogenesis and osteogenesis by fibroblast growth factor 18}

Zhonghao Liu, Jingsong Xu, Jennifer S. Colvin, et al.

Genes Dev. 2002, 16:

Access the most recent version at doi:10.1101/gad.965602

References This article cites 56 articles, 24 of which can be accessed free at: http://genesdev.cshlp.org/content/16/7/859.full.htmI\#ref-list-1

License

Email Alerting

Receive free email alerts when new articles cite this article - sign up in the box at the top Service right corner of the article or click here.

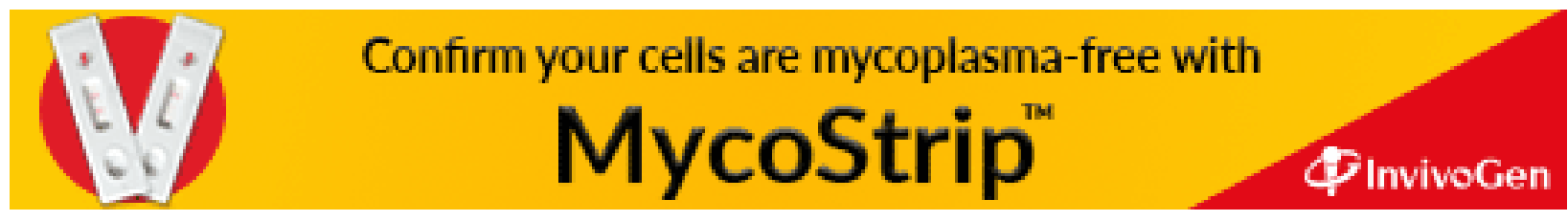

